\title{
Celso Furtado e o desenvolvimento regional
}

Clélio Campolina Diniz Professor do Cedeplar/UFMG

\section{Palauras-chave}

desenvolvimento regional, estrutura espacial, políticas públicas, nordeste.

Classificação JEL O18, R11, R12.

Key words

Celso Furtado, regional inequalities, Northeast (Brazil), SUDENE.

JEL Classification O18, R11, R12.

\section{Resumo}

O presente texto visa analisar as contribuições de Celso Furtado para a interpretação dos determinantes das desigualdades regionais e para a formulação de políticas de desenvolvimento para as regiões menos desenvolvidas. Toma como pano de fundo os antecedentes teóricos e as principais experiências mundiais de políticas de desenvolvimento regional, que serviram de referência para Celso Furtado. Mostra a originalidade de Furtado ao articular as questões de desigualdades regionais à natureza das estruturas subdesenvolvidas. Mostra os fundamentos teóricos e empíricos na análise sobre a questão nordestina, as diretrizes para a atuação da futura SUDENE, as pressões políticas e as insuficiências na condução da política de desenvolvimento para o Nordeste. Por fim, mostra a atualidade de Furtado, seja nas formulações anteriores à criação da SUDENE como nos desenvolvimentos teóricos posteriores. Nesses, Furtado supera a noção de região e passa a tratar de estruturas espaciais; introduz o papel central dos nódulos urbanos, de suas hierarquias e articulações, ou seja,o papel da rede urbana no comando e estruturação do território; do papel central da tecnologia e dos processos de inovação e; por fim, da necessidade de um esforço interdisciplinar, tanto para o entendimento dos problemas regionais quanto para a formulação de políticas e de sua implementação.

\author{
Abstract \\ This text analyzes the contributions by Celso Furtado \\ to interpreting the determinants of regional \\ inequalities and to the formulation of development \\ policies for less developed regions. \\ It uses a backdrop the theoretical antecedents and \\ principal global experiences of regional development \\ policies, which served as a reference for Celso Furtado. \\ It shows Furtado's originality when he linked \\ questions of regional inequality with \\ the nature of underdeveloped structures. \\ It shows the theoretical and empirical foundations in \\ the analysis of the Northeast question, guidelines for \\ the future SUDENE, political pressures and the \\ insufficiencies in the way development policies for the \\ Northeast are carried out. Finally, it shows how \\ Furtado's positions are still relevant, whether in the \\ formulations prior to the creation of SUDENE \\ or in the later theoretical developments. In these, \\ Furtado overcomes the notion of region and begins \\ to examine spatial structures; \\ he introduces the central role of urban nodes, \\ of their hierarchies and articulations; \\ in other words, the role of the urban network in the \\ command and structuring of the territory; \\ of the central role of technology and innovation \\ processes, and finally, of the need for an \\ interdisciplinary effort for both understanding \\ regional problems as well as for the formulation \\ of policies and their implementation.
}




\section{1_Antecedentes: origens, generalização, crise e retomada do planejamento e das políticas regionais}

Até a Segunda Guerra Mundial, a questão regional era predominantemente tratada como uma matéria de localização das atividades agrícolas e industriais, conforme comprovam os clássicos trabalhos de Von Thune (1816: 1966), Weber (1907: 1969) e Losch (1933: 1954) ou da oferta de serviços e da consequente hierarquia das centralidades urbanas, na formulação de Christaller (1939: 1966). A questão urbana ainda não havia emergido como um problema social e político, à exceção dos Estados Unidos, como bem retratam os trabalhos da Escola de Chicago (Park, 1926; Wirth, 1928; Munford, 1938).

A primeira experiência mundial de planejamento regional pode ser considerada como tendo origem na União Soviética, através do seu Plano de Eletrificação Nacional, estabelecido em 1925. Aquele plano definia a construção de várias usinas hidroelétricas, prevendo seu aproveitamento como base para o desenvolvimento regional e de sua interligação futura. ${ }^{1}$ A Comissão Nacional de Planejamento, criada na União Soviética, em 1928, introduziu a dimensão regional e a preocupação geopolítica de ocupação da Sibéria, presente desde Catarina, a
Grande. Durante a Segunda Guerra Mundial, essa preocupação se tornou central, com a invasão alemã e com a alta concentração populacional e produtiva na Rússia europeia. A estratégia de defesa territorial levou à transferência de várias atividades para trás dos Urais, com a constituição de complexos produtivos voltados para o aproveitamento de recursos naturais e o planejamento do desenvolvimento de várias cidades na Sibéria, com localização de atividades industriais, especialmente industrial-militar. Mais tarde, foi também planejado o desenvolvimento de centros urbanos dotados de serviços científicos e culturais como base para o desenvolvimento tecnológico, cujo melhor exemplo é a cidade científica de Akademgorodok, em Novosibirsk (Nekrasov, 1971; Castells e Hall, 1994).

A crise de 1929, ao provocar generalizada recessão econômica no mundo capitalista, colocou às claras o problema das desigualdades regionais na maioria dos países industrializados, as quais vinham se formando desde o século anterior, mas não eram explicitadas A tomada de consciência dessas desigualdades e a mudança na concepção do papel do Estado, com a revolução keynesiana e o avanço das técnicas e práticas de planejamento, promoveram a criação de políticas de redução das desigualdades regionais e de reordenamento
Aquele plano exerceu forte influência sobre o Plano de Eletrificação de Minas Gerais, elaborado em 1948 e implantado com a criação da Cemig, a partir de 1952. Ver Plano de Eletrificação, 1949 (Diniz, 2008). 
do território em vários países, com a criação de instituições específicas para a implementação dessas políticas. O caso mais claro foi o dos Estados Unidos, com a criação do TVA (Tennesse Vale Authority), em 1933, como parte do New Deal. O TVA introduziu uma nova sistemática de planejamento com $\mathrm{o}$ intuito de promover o desenvolvimento da região, composta de seis Estados. Os objetivos eram amplos e generalizados: obras para controle de cheias; construção de usinas hidroelétricas; desenvolvimento da navegação; transporte rodoviário; expansão e modernização da agricultura, inclusive programas de irrigação; crescimento e modernização da indústria; desenvolvimento urbano e dos serviços.

No pós-guerra, além da continuidade da política e dos programas do TVA, foram criados programas para outras bacias hidrográficas, estabelecida a Area Redevelopment Administration (ARA), em 1961, transformada em Economic Development Area (EDA), e criado o programa especial para os Apalaches, ambos em 1965. Essas instituições e os respectivos programas estabeleciam créditos e critérios especiais para alavancar o desenvolvimento regional. Naquele momento, havia se generalizado a prática do planejamento e das políticas regionais nos Estados Unidos, com grande influência sobre o sistema acadêmico-universitário e a concepção de programas de pós-graduação em desenvolvimento regional e urbano em várias universidades (Cumberland, 1973; Rothblat, 1971; Chinitz, 1969; Friedman, 1961; Isard, 2003).

Ainda antes da Segunda Guerra, na Inglaterra, a crise e a estagnação das regiões mineradoras e das áreas da velha industrialização pesada do norte do país, em contraste com a concentração industrial em Londres e seus arredores, trouxeram à tona o que ficou conhecido como a "divisão norte-sul”. Como decorrência, foi instituída a Comissão Barlow (1937-40), da qual nasceu, no pós-guerra, a política orientada para a recuperação e expansão da indústria da região norte (Hall, 1975).

$\mathrm{Na}$ Itália, a diferença entre os ritmos de desenvolvimento entre o norte e o sul do país tornou-se um problema grave, especialmente na fase de redemocratização do pós-fascismo. Em função disso, foi criada a Cassa del Mezzogiorno, em 1950, e uma ambiciosa política de industrialização para o sul da Itália. Essa política introduziu a sistemática de uso de incentivos fiscais para o barateamento da formação de capital e da produção, a qual foi assimilada e generalizada para outros países, a exemplo do sistema de incentivos fiscais para a industrialização do Nordeste do Brasil, por ocasião da criação da Sudene (Carvalho, 1979). Pos- 
teriormente, a reavaliação dessas políticas demonstrou as dificuldades de o Sul competir com o Norte, pelo dinamismo do último, caracterizando as dificuldades de superar o dualismo (Chenery, 1964; Amendola e Barata, 1978). Posteriormente, houve uma controvertida interpretação de que o desenvolvimento do Sul havia sido obstaculizado pela falta de capital social (Putnam, 1993).

$\mathrm{Na}$ França, a grande concentração populacional em Paris e o esvaziamento do campo levantaram o alerta para os riscos dessas tendências. Esse fenômeno está bem retratado no célebre livro de Gravier (2003) "Paris e o deserto francês", no qual o autor indica, em tom dramático e moralista, as consequências dessa concentração. A fim de enfrentar esse desafio, foi estabelecida ambiciosa política de desconcentração produtiva e de reordenamento do território, através de um conjunto de instrumentos. Entre esses, destacam-se a orientação dos investimentos das empresas estatais para regiões selecionadas e um audacioso e diversificado programa de infraestrutura, enfaticamente implementado a partir do final da década de 1940 (Datar, 2003). Após vários ajustes institucionais, foi criada a poderosa Delegation Dámanagement du Territoire (Datar), em 1963 (Datar, 2003). Entre as novas políticas e objetivos, ressalta-se o fortalecimento de uma rede de cidades, denomina- das "metrópoles de equilíbrio", com concentração de investimentos industriais e equipamento público, com destaque para aqueles de natureza cultural e educacional.

A generalização das políticas regionais nos países centrais foi assimilada pelos países periféricos. $\mathrm{Na}$ América Latina, a maioria dos países criou programas específicos de desenvolvimento regional, a exemplo dos programas de fronteira e de bacias, no México; da região de Guayana, na Venezuela; do Cuyo e da Patagônia, na Argentina. Segundo levantamento realizado por Sthor (1972), à época foram listados 73 planos ou programas de desenvolvimento regional nos países latino-americanos. No conjunto dessas políticas, cabe destaque às políticas brasileiras para o Nordeste e para a Amazônia, o que será tratado de forma mais detalhada em outra parte deste trabalho.

Ao lado da continuação e da generalização das políticas de desenvolvimento regional, foi desenvolvido grande esforço de interpretação teórica sobre a questão das desigualdades regionais e da concentração, bem como de metodologias e técnicas de planejamento e de intervenção pública. Esse esforço pode ser sintetizado no que ficou conhecido como duas "escolas" de pensamento. Uma delas resgatou a tradição germânica das teorias da localização e adaptou-a ao pensamento econômico neo- 
$\ldots \ldots$

2 A obra de Perroux foi produzida ao longo das décadas de 1940 e 1950 , em vários artigos, e uma grande síntese encontra-se em Economia do século XX (Perroux, 1967). clássico, constituindo a chamada "ciência regional", inclusive com a criação da Associação de Ciência Regional (Regional Science Association), sob a liderança de Walter Isard. Essa "escola" trabalhou com noção de modelos de equilíbrio, com ênfase no papel dos custos de transporte, em mercados concorrenciais, desenvolvendo, paralelamente, um conjunto de técnicas de análise regional, entre as quais os modelos de insumo-produto. Essas contribuições estão sintetizadas em dois livros que se transformaram em verdadeiras "bíblias" da denominada "ciência regional", a saber: Location and space economy $e$ Methods of regional and interregional analysis (Isard, 1956 e 1960). Posteriormente, Isard organizou a história da ciência regional e da associação de ciência regional (Isard, 2003).

A outra "escola" foi desenvolvida na França, sob liderança de François Perroux. Partindo da noção de economia dominante e empresa dominante e dos efeitos interindustriais, foi desenvolvido o conceito de polo de crescimento e do papel central da empresa motriz para o crescimento desses polos. Na sua concepção de empresa motriz, Perroux havia recebido forte influência de Schumpeter, com o conceito de inovação, já que Perroux havia traduzido, em 1935, a Teoria do Desenvolvimento Econômico, de Schumpeter, do alemão para o francês. O conceito de dominação e de po- lo de crescimento levaram Perroux à concepção das diferentes naturezas do espaço, com sua ideia de espaço homogêneo, espaço polarizado e espaço plano (Perroux, 1967). ${ }^{2}$ Essas noções de espaço, sem contiguidade geográfica, foram adaptadas por Boudeville (1969), com a concepção de região homogênea, região polarizada e região plano, que serviram de base e critério para a regionalização do território e para o estabelecimento de políticas regionais.

A linha do desenvolvimento polarizado e desequilibrado recebeu grande contribuição de vários autores que se tornaram clássicos, como Myrdal (1957), Hirschman (1958), Kaldor (1966 e 1970), entre outros. Esses autores analisaram os efeitos da polarização na criação e na manutenção das desigualdades regionais e apontaram possíveis saídas. A partir da década de 1960, a criação e o fortalecimento de polos de desenvolvimento passaram a ser generalizadamente utilizados como metodologia e instrumento de desenvolvimento regional na maioria dos países. Nos últimos anos, esses polos ganharam nova roupagem, como a concepção de distritos industriais, "clusters", parques tecnológicos, entre outras denominações.

Embora essas duas "escolas" partissem de proposições teóricas e analíticas distintas, elas têm em comum a ideia de re- 
lações interindustriais ou insumo-produto, como elemento central no processo de desenvolvimento regional e da criação de externalidades. Em torno dessas duas "escolas", foram derivadas várias linhas de interpretação e de ação à escala mundial.

Após o auge da produção teórica e da implementação de políticas de desenvolvimento regional, nas décadas de 1950 e 1960, a atividade entrou em crise. Entre os elementos explicativos dessa crise, podem ser listados: a) o sucesso da expansão econômica do pós-guerra e a redução da preocupação com a questão regional; b) reações político-ideológicas contra a intervenção do Estado na economia; c) insatisfação e crítica dos resultados das políticas regionais pelos grupos de esquerda; d) incapacidade teórica de explicar os novos fenômenos (desindustrialização, emergência de novos centros baseados em alta tecnologia, mudanças na divisão internacional do trabalho, com os NICs); e) enfraquecimento das políticas regionais nos Estados Unidos, com a ascensão de Nixon e dos governos republicanos; f) enfraquecimento das políticas regionais, por países, na Europa, com o avanço da União Europeia; g) crise do Estado interventor, com déficit público e processos inflacionários; h) alegação de corrupção em várias das instituições encarregadas das políticas regionais; i) desenho de uma nova visão do papel do Estado, o que ficou conhecido como "neoliberalismo".

No bojo deste último ponto, foi desenvolvida a corrente de pensamento do crescimento endógeno que procurava demonstrar que o mercado, deixado livre, levaria à convergência de rendas entre países e regiões. Caberia ao Estado resolver os problemas de educação, dotação de infraestrutura e estabilidade político-institucional (Romer, 1994; Sala-y-Martin, 1996).

Passada a tormenta crítica e o desânimo com as políticas regionais, nas décadas de 1970 e 1980, a questão voltou à tona, teórica e praticamente, a partir da década de 1990. Do ponto de vista prático, os avanços da União Europeia mudaram a natureza das políticas regionais. Além da diversidade interna em cada país, as diferenças entre países passaram a ser vistas como problemas regionais de escala transnacional para o conjunto da região (União Europeia). Isso obrigou a União Europeia a avançar na formulação e prática da política regional. Simultaneamente, os problemas de integração regional em outras partes do mundo e o arrefecimento das esperadas convergências de renda recolocaram a política regional na agenda das regiões e dos governos. Por outro lado, as aceleradas mudanças tecnológicas e a emergência de novos centros produtores baseados em tec- 
nologias avançadas abriram a corrida para a busca da inovação como mecanismo de desenvolvimento regional (Diniz e Gonçalves, 2005; Diniz, Santos e Crocco, 2006).

Do ponto de vista teórico, a crescente integração da economia mundial, a criação de regiões preferenciais de comércio e o aumento dos fluxos comerciais recolocaram a questão do comércio internacional como um assunto do comércio inter-regional. A integração da economia mundial superou as fronteiras nacionais e estabeleceu um sistema de fluxos onde as localidades se articulam diretamente, recolocando a questão das economias de aglomeração e das externalidades como elementos centrais nos padrões locacionais e no sucesso competitivo. Nessa linha de raciocínio, entra de cheio o economista Paul Krugman (1991) com uma nova teoria da relação centro-periferia, introduzindo concorrência imperfeita e economias de escala na geração de externalidades e dos retornos crescentes para explicar os padrões de concentração territorial da produção. Paralelamente, a geografia econômica passou a buscar diferentes elementos explicativos para o entendimento da reorganização territorial da produção à escala mundial (Storper, 1995; Swyngedouw, 1989; Markusen, 1985; Brenner, 1999). Estão, pois, postas as condições para uma vigorosa retomada do debate teórico e das políticas de desenvolvimento regional, no mundo e no Brasil.

\section{2_A questão regional brasileira}

\subsection{As secas nordestinas, a geopolítica amazônica e a origem das ações regionais}

A preocupação com o problema regional no Brasil esteve presente desde o século XIX, embora não tivesse essa denominação, em função das consequências sociais das secas, no Nordeste, e da necessidade de controle do território da Amazônia, como retratam as várias comissões e tentativas de políticas realizadas desde aquele século.

Para o caso nordestino, como decorrência das secas, em 1877 foi criada a Comissão Imperial, encarregada de analisar o problema e propor soluções. Aquela comissão sugeriu o desenvolvimento dos transportes, a construção de barragens e a transposição do rio São Francisco. As ações foram, no entanto, limitadas e lentas, enquanto se aprofundava o problema social da região. Estima-se que, como consequência das secas e dos problemas sociais, tenham morrido entre 100 e 200 mil pessoas nas últimas décadas do século XIX. Estima-se também que, entre o final do século XIX e início do século XX, aproximadamente 500 
mil pessoas tenham se transferido ou foram transferidas para a região amazônica, na expectativa das oportunidades de trabalho vinculadas à exploração da borracha, que emergia como novo produto de exportação (Furtado, 2001; Cano, 1977 e 1985). Em 1904, foram criadas comissões para analisar o problema das secas no Ceará e no Rio Grande do Norte e, no mesmo ano, criada a Inspetoria de Obras Contra as Secas (IOCS), transformada em Inspetoria Federal de Obras Contra as Secas (IFOCS), em 1906, e em Departamento Nacional de Obras Contra as Secas (DNOCS), em 1945. Em 1920, havia sido criada a Caixa Especial de Obras de Irrigação de Terras Cultiváveis no Nordeste do Brasil, com 2\% do orçamento da União. Em 1923, a Constituição Federal fixou em 4\% do orçamento federal para o controle das secas. Em 1945, seguindo a experiência do TVA, foi criada a Companhia Hidroelétrica do São Francisco. A nova Constituição Federal, aprovada em 1946, estabeleceu vinculações orçamentárias específicas para o desenvolvimento das regiões Nordeste e amazônica. Por essa razão, foi criada a Comissão de Desenvolvimento do Vale do São Francisco (Codevasf), em 1948. Em 1951, seria instituído o Banco do Nordeste do Brasil (BNB).

No que se refere à Amazônia, em 1912, foi criada a Superintendência de De- fesa da Borracha, preocupada com a concorrência asiática, transformada em Instituto Internacional da Hileia Amazônica, em 1945; em Superintendência do Plano de Valorização Econômica da Amazônia (SPVEA), em 1953; e em Superintendência de Desenvolvimento da Amazônia (Sudam), em 1966. Em 1942, no bojo dos acordos de Washington, foi criado o Banco de Crédito da Borracha, transformado em Banco de Crédito da Amazônia, em 1957, e em Banco da Amazônia S.A. (Basa), em 1966. Em 1967, seria criada a Suframa.

A generalização da política regional levou à criação de superintendências para as demais regiões do País, a saber: Superintendência do Plano de Valorização Econômica da Região da Fronteira Sudoeste do País (SPVERFSP), em 1961, transformada em Sudesul, em 1967; a Comissão de Desenvolvimento do Centro-Oeste (Codeco), em 1961, transformada em Sudeco, em 1967.

Conclui-se que o Brasil foi pioneiro na busca de instrumentos e ações para alavancar o desenvolvimento do Nordeste e da Amazônia. A primeira, pelas graves crises sociais e pela força regionalista de sua elite. A segunda, pela preocupação com o controle político do vasto território amazônico. As críticas a essas instituições, a alegada existência de corrupção e as mudanças na concepção e no papel do Estado, duran- 
3 Embora Lucas Lopes mencione em suas memórias que não estava interessado em macroeconomia e que não conhecia o trabalho de Furtado, o Programa de Metas foi fundamentalmente desenvolvido e gerido dentro do BNDE. Como as equipes do BNDE estavam também envolvidas no Grupo de Trabalho Cepal/BNDE, não há como desvincular essas experiências. A Comissão Mista Brasil-Estados Unidos, que deu origem ao BNDE e da qual Lucas Lopes fazia parte, havia sido extinta. Com a posse de JK, Lucas Lopes assume a presidência do BNDE e a secretaria do Conselho de Desenvolvimento, responsável pela condução do Programa de Metas. te a era neoliberal, levaram ao esvaziamento e posterior fechamento da maioria delas. Foram mantidos a Suframa, o BNB e o Basa. A Sudene foi transformada em Adene e, posteriormente, recriada a Sudene. Movimento semelhante ocorreu com a Sudam, transformada em ADA e novamente recriada. A Sudeco foi extinta e recriada.

\subsection{Celso Furtado, o subdesenvolvimento e a questão regional}

A origem nordestina, a trajetória intelectual e pessoal de Celso Furtado e o momento histórico do pós-Segunda Guerra se conscientizaram para o problema do subdesenvolvimento e, por consequência, das desigualdades dos ritmos de desenvolvimento entre os territórios, seja entre nações, seja entre espaços sub-regionais dentro de cada país. Inicialmente, seu esforço se concentrou na busca do entendimento do Brasil, através da análise da sua formação histórica e dos condicionantes estruturais que essa herança havia deixado, refletido na sua tese de doutoramento sobre a economia colonial brasileira, concluída em 1948 (Furtado, 2001).

Posteriormente, Furtado aprofundou seus estudos sobre o subdesenvolvimento, durante o período em que trabalhou na Comissão Econômica para a América
Latina e o Caribe (Cepal), entre 1949 e 1957, durante o qual manteve profícua convivência profissional com Raul Prebish. $\mathrm{Na}$ qualidade de chefe da Divisão de Desenvolvimento da Cepal, ele realizou vários trabalhos sobre países específicos e aprofundou sua interpretação sobre a problemática do subdesenvolvimento latino-americano. No Grupo de Trabalho Cepal/BNDE, Furtado retomou seus estudos sobre a economia brasileira, cujo relatório influenciou o diagnóstico e a montagem do Programa de Metas do Governo Juscelino Kubitschek. ${ }^{3}$ Nesse período, Furtado consolida sua formação teórica e sua capacidade de interpretação do subdesenvolvimento como uma questão histórico-estrutural. No ano acadêmico de 1957/58, como visitante e fellow do Kings's College, em Cambridge, Furtado organiza suas reflexões, o que seria retratado nas obras seminais publicadas nos anos seguintes. Entre essas obras, destacam-se Formação econômica do Brasil, publicada em 1959; Desenvolvimento e subdesenvolvimento, publicada em 1961 e republicada em versão expandida como Teoria e política do desenvolvimento econômico, em 1967, e Dialética do desenvolvimento, publicada em 1964, às vésperas do golpe militar.

No nosso entendimento, o livro Formação econômica do Brasil pode ser lido como a primeira interpretação do desenvolvimen- 
to regional brasileiro. ${ }^{4}$ Segundo Furtado, sua análise do processo histórico de formação da economia brasileira parte de uma visão ampla, procurando captar a cadeia de causalidades nesse processo de desenvolvimento.

A obra se concentra na análise dos três grandes ciclos e atividades: açúcar, no Nordeste; ouro e diamante, em Minas Gerais, em Goiás e no Mato Grosso; e café no Sudeste (Rio de Janeiro, Espírito Santo, Minas Gerais e São Paulo). Além do próprio efeito dessas atividades e suas articulações locais, os efeitos de expansão e declínio dessas deram origem a movimentos de ocupação territorial, configurando o mapa regional brasileiro. No caso do Nordeste, as crises açucareiras e a invasão holandesa provocaram movimentos de deslocamento populacional para o Norte, com espasmos de ocupação no Ceará, no Maranhão e no Pará. No final do século XIX, os deslocamentos populacionais se dirigiram à Amazônia, alargando a dimensão da ocupação territorial. No caso do ouro e do diamante, além da extensão das áreas de exploração (Centro e Vale do Jequitinhonha, em Minas Gerais, Centro de Goiás e Mato Grosso), a necessidade de alimentos, animais de carga e couro fortaleceu a integração entre as regiões mineradoras, São Paulo e Oeste de Minas (passagem para Goiás e Mato Grosso), e o Sul do Brasil. No que se refere ao café, este se expande procurando as terras mais apropriadas (Rio de Janeiro, Espírito Santo, Minas Gerais, São Paulo e Paraná). A introdução do trabalho livre, os efeitos de encadeamento da atividade cafeeira, os processos migratórios, a demanda de alimentos, insumos e matérias-primas e a expansão ferroviária exerceram forte impacto na integração territorial do País.

Nesse sentido, pode-se concluir que a interpretação do desenvolvimento brasileiro, entre os séculos XVI e XX, contida na Formação econômica do Brasil, pode ser lida como uma interpretação das condicionantes, dos efeitos e dos resultados da dinâmica econômica e populacional sobre a dinâmica territorial do País.

\section{3_Celso Furtado e a questão nordestina}

As experiências mundiais e brasileira, antes indicadas, eram de amplo conhecimento de Furtado, seja pela sua condição de estudante de doutorado na Sorbonne, em Paris, no imediato pós-guerra, pela sua passagem por Cambridge, na Inglaterra, seja pelo trabalho na Cepal. A oportunidade aberta com a incumbência recebida do presidente JK, para pensar uma solução para o dramático problema social e econômico do Nordeste brasileiro, ressaltado, uma vez mais, com as graves secas de 1958, permitiu a Celso Furtado a

\author{
4 As obras de Simonsen \\ (1944) e Prado Junior (1996) \\ trazem os elementos \\ explicativos da ocupação \\ territorial no Brasil \\ (açúcar, pecuária, mineração, \\ café, borracha, mate etc.). \\ No entanto, Furtado foi o \\ primeiro a articular esses \\ fundamentos com o \\ desenvolvimento regional \\ e com a formação de \\ estruturas subdesenvolvidas.
}


sistematização de suas ideias. Resgatando a própria interpretação sobre o desenvolvimento brasileiro e a interpretação da Cepal (1950), Furtado formula um sintético, porém profundo, diagnóstico das razões do subdesenvolvimento nordestino e cria as bases para a sua superação. No diagnóstico, constante do relatório do GTDN, elaborado em 1959 (GTDN, 1967), Furtado começa por negar as visões correntes de que o problema econômico e social do Nordeste decorria das secas. Negava, assim, a solução hidráulica através da construção de açudes, o que vinha sendo feito pelo governo federal através do DNOCS, mas que beneficiava apenas os proprietários de terra. Contesta também a visão de que o subdesenvolvimento era uma etapa do processo de desenvolvimento econômico, como formulado por Rostow (1959) e amplamente aceito na literatura internacional. Ao contrário, demonstra que o subdesenvolvimento é o resultado de uma formação histórico-estrutural particular e que ele só pode ser superado por transformações estruturais.

Toma os fundamentos históricos da colonização regional como determinante da dicotomia social da região. Em primeiro lugar, na faixa litorânea úmida, a empresa agrícola exportadora de açúcar estava base- ada em trabalho escravo. Quando esse foi formalmente extinto, no final do século XIX, mantiveram-se relações de trabalho pré-capitalistas, por meio de diferentes formas de semiescravidão, semisservilismo, de "meia" e de cambão. Em segundo lugar, ao demandar animais de carga e alimentos, a economia exportadora criou a própria periferia no interior, a ela subordinada e dependente. O crescimento demográfico empurrava a população para terras mais áridas, agravando as próprias condições de subsistência. Em terceiro lugar, a fazenda do semiárido se baseava em uma população camponesa, sem terra e sem salário, a qual trabalhava para o dono da terra na forma de "meia" (partilha da produção) para as culturas de exportação, principalmente algodão e, em compensação, podia produzir a sua subsistência. Essas três características perduraram por séculos, caracterizando uma situação estrutural de subdesenvolvimento. Ou seja, mantinha-se uma estrutura agrária dual e arcaica, com relações mercantis para fora, ao lado de relações de trabalho pré-capitalistas ou não mercantis, especialmente das atividades voltadas para a subsistência.

Adicionalmente, as elites regionais, ligadas ao setor exportador ou ao aparelho de Estado, assumiam padrões de consumo cosmopolitas, incompatíveis com o nível da renda regional. Nessa condição, os exce- 
dentes eram consumidos e não investidos, impossibilitando a sustentação de um processo de desenvolvimento. Esse era também um dos fundamentos da má distribuição de renda, tema recorrentemente retomado na maioria dos seus trabalhos posteriores, mas, de maneira enfática, em Subdesenvolvimento e estagnação na América Latina e em Análise do modelo brasileiro (Furtado, 1966 e 1972).

À sua interpretação teórica do subdesenvolvimento, Furtado adaptou a análise cepalina de relação centro-periferia, buscando demonstrar que a relação entre o Nordeste e o Centro-Sul do Brasil tinha um efeito extremamente negativo sobre a economia da primeira. Furtado deixa, portanto, de analisar a região de forma isolada e passa a examiná-la por meio da articulação de sua estrutura interna com o exterior e com a região Centro-Sul do País. Nega os princípios das vantagens comparativas naturais ou ricardianas, baseada na dotação regional de fatores (terra e trabalho) e o desenvolvimento dessa corrente pelo pensamento neoclássico. De forma semelhante à análise da Cepal para as relações entre países centrais e periféricos, a relação comercial entre o Nordeste e o Centro-Sul do Brasil tinha um duplo efeito de transferência de renda da primeira para a segunda e de impedimento do processo de industrialização do Nordeste.
Por um lado, os superávits comerciais do Nordeste com o exterior eram utilizados para financiar as importações da região Centro-Sul do Brasil, beneficiando esta última. O crescimento e a concentração industrial na região Centro-Sul, a política cambial protecionista e a manutenção de uma economia primária no Nordeste faziam com que este importasse bens industrializados do Centro-Sul, a preços mais altos que os do exterior, e exportasse matérias-primas e alimentos para este, Centro-Sul. Adicionalmente, a indústria tradicional do Nordeste havia sido afetada pela construção da rodovia Rio-Bahia, facilitando a penetração dos bens industriais do Centro-Sul no Nordeste e devastando a indústria têxtil dessa região.

Esse duplo mecanismo de transferência de renda provocava um efeito sobre a economia nordestina semelhante ao efeito dos países centrais sobre a periferia, caracterizado no clássico diagnóstico da deterioração dos termos de intercâmbio da Cepal (Cepal, 1949). Assim, a política de industrialização do Brasil era benéfica para a região Centro-Sul e nefasta para o Nordeste. Furtado negava o argumento de que esses efeitos fossem compensados pelas transferências públicas de recursos via governo federal. Alegava que as transferências, mediante mecanismos comerciais, destina- 
$\ldots \ldots \ldots \ldots$

5 Esses argumentos foram contestados por vários autores, como sintetiza Cano (1985), sem, contudo, negarem a relação centro-periferia entre o Nordeste e o Centro-Sul do País.

6 Manheim (1951) analisa as crises do século XX (duas guerras, Revolução Russa, nazismo), refuta as soluções totalitárias (stalinismo e fascismo) e defende a reforma do sistema através do planejamento. Os trabalhos de Manheim tiveram grande influência sobre Celso Furtado. vam-se ao financiamento de investimentos produtivos no Centro-Sul, e que as transferências públicas para o Nordeste tinham caráter assistencial e, portanto, destinadas ao consumo pessoal, sem criar capacidade produtiva. A consequência de sua análise era de que a distância entre o Nordeste e o Centro-Sul tenderia a aumentar. ${ }^{5}$ Aliás, essa afirmativa estava corroborada nos dados por ele utilizados mostrando que a renda per capita do Nordeste havia caído de 48\% para 37\% da média nacional, entre 1948 e 1956, e que o peso da região no total da renda nacional havia caído de 15\% para $13 \%$ no mesmo período.

$\mathrm{Na}$ mesma linha do diagnóstico da Cepal, ele argumentava que a única saída para o Nordeste seria através da industrialização. Concluía de forma dramática "caso se demonstre que a solução é inviável, não restaria ao Nordeste senão a alternativa entre despovoar-se ou permanecer como região de baixíssimo nível de renda" (GTDN, 1967). Enfatizava a importância do progresso técnico e as dificuldades para a sua geração e assimilação nas regiões subdesenvolvidas. Por essa razão, no diagnóstico e nas ações propostas, estava explícita a ideia de criação de centros endógenos de decisão e de industrialização. Ou seja, de uma industrialização autônoma e de fortalecimento da burguesia regional. Além de sua forte cren- ça na industrialização, o argumento era reforçado pelos problemas climáticos e pelas limitações de terras agricultáveis, pelo menos com os padrões tecnológicos da época. Embora sua proposta contivesse duas grandes diretrizes para a transformação do setor agropecuário na faixa úmida e no semiárido, Furtado propunha uma saída para o excedente de trabalho por meio do deslocamento da população para uma nova fronteira agrícola no Estado do Maranhão.

As diretrizes do Plano de Desenvolvimento para o Nordeste, contidas no relatório do GTDN, podem ser sintetizadas em quatro grandes linhas ou programas: industrialização; transformação da agricultura da faixa úmida; transformação da economia do semiárido e deslocamento da fronteira agrícola para o Maranhão. Observase, portanto, que o plano de Furtado tinha caráter reformista e modernizador, com forte influência das visões keynesiana, de intervenção do Estado para a solução dos problemas econômicos e sociais, e de Manheim, ${ }^{6}$ que defendia o planejamento como solução para a busca da democracia e da justiça social.

As tentativas de implementação dessas diretrizes vão estar contidas nas primeiras ações do Conselho de Desenvolvimento do Nordeste (Codeno), criado logo após a conclusão do relatório do GTDN, em 1959, 
e no Primeiro Plano Diretor da Sudene, elaborado logo após sua criação, mas somente aprovado em 1961.

\section{4_ A Sudene, as dificuldades políticas e as falhas de orientação}

O Codeno e a sucessora Sudene iniciaram suas ações sob a liderança de Celso Furtado e dentro das linhas estabelecidas pelo relatório do GTDN. Essas linhas de ação foram ampliadas e detalhadas no I Plano Diretor preparado pela Sudene, em 1960, para o período 1961-1963, o qual assumiu uma postura de planejamento compreensivo, incluindo infraestrutura, reestruturação agrícola, colonização, desenvolvimento industrial e mineral, oferta de alimentos, saúde pública, educação, levantamentos cartográficos, entre outros aspectos.

No entanto, desde sua criação, a Sudene enfrentou fortes reações político-ideológicas de parcela significativa das elites empresariais, políticas e intelectuais do Nordeste, no que se refere às suas linhas de orientação e proposições. As atas do Conselho Deliberativo da Sudene, para o período, detalhadamente analisadas por Lima (2008), confirmam essas dificuldades. O projeto da Lei de Irrigação, enviado ao Congresso, em 1959, nunca foi aprovado, uma vez que trazia os meios para o contro- le do uso da terra e da água, bases para a reforma agrária. Isso obviamente suscitou as mais diferentes reações das elites nordestinas. Igualmente, o projeto do I Plano Diretor sofreu fortes reações dentro do próprio Conselho Deliberativo da Sudene e, posteriormente, dentro do Congresso Nacional, atrasando sua aprovação. As reações eram diversificadas: governadores de Estado, Forças Armadas, DNOCS, elites políticas e empresariais e também do sociólogo Gilberto Freyre (Lima, 2008). Assim, a Sudene seguia pelas linhas de menor resistência.

As mudanças políticas decorrentes do golpe militar de março de 1964 alteraram a ênfase nas linhas de ação. Essas foram concentradas em apenas duas frentes: expansão da malha de infraestrutura (transportes, energia elétrica e saneamento) e suporte à industrialização. A primeira, com a aplicação direta de $60 \%$ a 70\% dos recursos aprovados nos Planos Diretores. A segunda, pelo sistema de incentivos fiscais canalizados através do mecanismo conhecido como "34/18", q que conjugava a isenção tributária sobre a produção e o financiamento dos investimentos mediante o uso de parcela do imposto de renda devido pelas empresas, transformados em debêntures e, portanto, não reembolsáveis. Ficou estabelecido também que tanto os recursos orçamentários quanto os recursos advin-
A Lei Federal n. 3.692, de 1959, que criou a Sudene, estabeleceu em seu art. 18 os incentivos fiscais (isenção tributária) para projetos industriais novos e de expansão a ser implementados no Nordeste. A Lei Federal n. 3.995, de 1961, que aprovou o I Plano Diretor, estabeleceu no seu art. 34 o direito de as empresas brasileiras (pessoas jurídicas) vincularem parcela do imposto de renda a ser pago para aplicação em projetos industriais no Nordeste. Esses dois mecanismos eram utilizados de forma conjunta, conhecidos como "arts. 34/18". 
dos da isenção de imposto de renda para aplicação em projetos de investimento no Nordeste deveriam ser depositados no Banco do Nordeste do Brasil, reforçando seu papel de agente financeiro.

Infraestrutura e incentivos ao crescimento industrial atendiam aos interesses da classe dominante e do sistema empresarial. Reestruturação do setor agrícola, tanto na faixa úmida quanto no agreste e no semiárido, implicava reforma agrária. Essa era exatamente a reivindicação das correntes progressistas, tão bem representadas pelas Ligas Camponesas, organizadas pelo deputado Francisco Julião. A contenda foi resolvida com o golpe militar de 1964, que aplastou as reivindicações políticas da classe trabalhadora e de suas lideranças e liquidou a proposta de reforma agrária.

Nesse sentido, Oliveira (1977) diz que a Sudene foi criada em consonância com os interesses da burguesia industrial da região Centro-Sul do Brasil e articulada com os interesses da burguesia decadente do próprio Nordeste. Foi também uma forma de segurar a pressão das forças populares, cuja ação poderia apontar na direção de uma desintegração do País, pelos movimentos de caráter revolucionário que se despontavam na região, a exemplo das Ligas Camponesas. Na mesma linha, Cohn (1976) argumenta que a Sudene foi instituí- da para atender às necessidades de solucionar os problemas sociais e políticos do Nordeste. Assim, a Sudene teria vindo para mediar o conflito social e tornar possível a expansão capitalista do Brasil.

No entanto, essa é uma racionalização a posteriori. O próprio Oliveira argumenta que a Sudene foi um audacioso projeto de transformação estrutural da região. $\mathrm{O}$ resultado poderia ir a direções diferentes, dependendo das forças políticas que prevalecessem no processo. Além das reações internas contra o caráter reformista da Sudene, houve forte pressão internacional contra os movimentos de cunho socialista. $\mathrm{O}$ governo dos Estados Unidos, através da Aliança para o Progresso e da Usaid, liderou programas que visavam a bloquear os movimentos populares e o risco de uma revolução socialista no Brasil. Com o golpe militar de março de 1964, as forças populares foram controladas e dominadas. Predominou a orientação pela industrialização, pelo avanço da infraestrutura e pela modernização conservadora da agricultura, com a abertura de novas frentes proporcionadas pelo avanço da tecnologia, como a agricultura irrigada e a dos cerrados, afastando a ideia da reforma agrária.

Furtado (1989), em seu livro $A$ fantasia desfeita, confirma essas preocupações do governo americano ao relatar sua via- 
gem aos Estados Unidos e seu encontro com o presidente Kennedy, em 1961. Naquela ocasião, ficou claro o conflito de visões do presidente Kennedy, mais flexível, e do Departamento de Estado, mais radical. Acabou prevalecendo a orientação do Departamento de Estado, como ficou comprovado pela ação do governo americano, que agiu no sentido de minar a ação, o prestígio e o poder da Sudene no período que precedeu ao golpe militar de 1964.

Assim, a ação da Sudene foi esvaziada e alterada por três razões. A primeira foi $\mathrm{o}$ aniquilamento das propostas de reformas estruturais. Sem a reforma agrária, a estrutura de propriedade e exploração da terra continuou intocada. Com ela, os problemas de distribuição de renda e de melhoria das condições sociais. O segundo problema, pela drenagem dos recursos previstos no sistema de incentivos fiscais, ao ampliar a sua área de aplicação para a região amazônica, ainda em 1963, e para vários setores (turismo, reflorestamento) em todo o País, em anos posteriores. Em terceiro lugar, porque muitos projetos industriais aprovados nas primeiras etapas da Sudene tiveram funcionamento precário, levando ao encerramento das atividades. Em 1978, dos 763 projetos industriais que receberam incentivos, 104 estavam funcionando com problemas, e 88 haviam sido paralisados (Re- bouças et al., 1979). Não há clareza sobre as razões desses fracassos. Se por má concepção ou análise, se pela competição, ou se por erros ou desvios de conduta. Qualquer que seja a razão, o fechamento de muitas plantas acabou por desacreditar e desmoralizar a Sudene.

Nesse sentido, é questionável a orientação contida no GTDN e no I Plano Diretor, de ênfase em uma industrialização autônoma no Nordeste, seja porque a economia brasileira estava integrada e, portanto, o Nordeste teria que competir com as demais regiões do País, seja pela debilidade de sua burguesia industrial. Isso só poderia ser feito se atendesse aos interesses empresariais das demais regiões, o que acabou acontecendo pelo uso dos incentivos fiscais pelo empresariado de outras regiões; isso fortaleceria a capacidade empresarial da região e de fato vem acontecendo.

\section{3_Avanços posteriores e a atualidade de Celso Furtado}

Afastado do cargo e do País, Furtado se dedicou ao aprofundamento de sua interpretação do subdesenvolvimento e também da questão regional. Em 1967, publicou um artigo teórico sobre o desenvolvimento regional denominado "Intra-country discontinuities: towards a theory of spatial structu- 
res" (Furtado, 1967). Nesse artigo, além de uma reinterpretarão crítica dos principais pilares da Teoria do Desenvolvimento Regional, Furtado introduz pelo menos quatro grandes avanços ou superações das visões anteriores. Em primeiro lugar, supera a noção de região e passa a tratar da estrutura espacial, demonstrando as várias articulações inter e intraterritorial no processo de desenvolvimento, o que nos ajuda a entender a complexidade das relações entre agentes e atores no território. Em segundo lugar e articulado ao primeiro, enfatiza o papel da hierarquia de nódulos ou polos e a inter-relação entre esses. Ou seja, introduz, de forma explícita e direta, o papel do urbano e das cidades na estruturação e no comando do território, cuja importância e complexidade só têm se ampliado nos últimos anos. Em terceiro lugar, demonstra que as desigualdades são produtos das formas em que se introduzem e se distribuem as modernas tecnologias, vale dizer dos processos inovativos. Por fim, Furtado ressalta a complexidade dos fenômenos espaciais, propondo um esforço interdisciplinar como caminho para a formulação de uma teoria das estruturas espaciais.

Como um pensador engajado, Furtado trabalha a sua construção teórica como fundamento e base para a ação política.
Demonstra que as descontinuidades interregionais dentro de cada país são geradas pelos padrões locacionais, especialmente da indústria, e sua relação com as políticas macroeconômicas. Analisa a relação negativa entre concentração regional e distribuição de renda, demonstrando que os ganhos de produtividade tendem a se concentrar. Defende a criação de externalidades como forma de beneficiar, em conjunto, empresas e consumidores. Conclui mostrando que as mudanças espaciais dependem, fundamentalmente, de quatro fatores, a saber: a) do ritmo de crescimento econômico, cujo aumento possibilita maior elasticidade espacial; b) do número de novas plantas, especialmente de plantas motrizes; c) das plantas de processamento secundário, não dependentes de insumos e matérias-primas primárias; d) das economias de escala, as quais se ampliam com o progresso técnico. Para tudo isso, a expansão da infraestrutura funciona como pré-condição ou pano de fundo. Embora reconheça que as decisões são de natureza política, Furtado enfatiza uma abordagem interdisciplinar para uma teoria da estrutura espacial, com ênfase nos estudos sobre os processos de urbanização, dos custos de comutação, das migrações.

Nessa linha de interpretação, repensar a questão regional brasileira em termos atuais significa reinterpretar as estruturas 
espaciais e sociais atuais e suas tendências e conjugá-las com os objetivos econômicos, sociais e políticos da Nação.

$\mathrm{O}$ primeiro ponto a ser discutido está relacionado com a superação de se pensar regiões isoladas, para se pensar a estrutura espacial. Nesse sentido, uma política regional precisa ser concebida e formulada em uma perspectiva nacional, ainda que as diferentes regiões recebam tratamento diferenciado, em função de suas características e objetivos gerais. Assim, uma nova política regional, guiada pelos objetivos de coesão econômica e social, necessitaria também ser pensada em função da coesão territorial. A coesão territorial, por sua vez, passa pelo menos por quatro dimensões da integração. Integração territorial (no sentido físico), integração econômica (como complementaridade produtiva entre as sub-regiões), integração social (que considere a distribuição de renda, a geração de emprego e a incorporação social), integração política (no sentido da recostura do pacto federativo).

Adicionalmente, há que ser considerada a integração com a América Latina (territorial, econômica, social e política), a questão ambiental e a geopolítica brasileira e sul-americana. Tudo isso implicaria a busca de um novo ordenamento do território que caminhasse no sentido de redução das grandes desigualdades nos padrões de ocupação territorial do País e apontasse no sentido de um país mais integrado.

Do ponto de vista operacional, pensar uma política nacional de desenvolvimento regional implica pensar em uma nova regionalização do país para efeitos de política pública, em geral, e da política regional, em particular. No caso do Brasil, a regionalização atual com as cinco macrorregiões, que continua como base para as políticas regionais, está superada, exigindo uma nova divisão territorial do País. Uma nova regionalização deveria considerar três critérios complementares e articulados: econômico, ambiental e político.

O critério econômico deve ter como referência básica os efeitos de polarização exercidos pelas cidades, a partir de cuja hierarquia se definiriam as escalas de polarização, as centralidades e suas áreas complementares. O critério ambiental deveria buscar o ajuste dos recortes territoriais às necessidades de aproveitamento econômico do patrimônio natural e da sustentabilidade ambiental. Por fim, o critério de representação política deveria preservar a relação entre o recorte territorial e a identidade cultural e política de seus habitantes e suas instituições e, ao mesmo tempo, os aspectos de geopolítica e soberania nacional. Assim, respeitada a divisão político-admi- 
nistrativa do País em Estados e municípios, tornar-se-ia necessário estabelecer pelo menos duas escalas operacionais: uma macro e outra mesorregional, o que está proposto em recente trabalho realizado pelo Cedeplar e publicado pelo Ministério do Planejamento (2008).

Um segundo aspecto está relacionado com as fontes de financiamento e sua operacionalização institucional. O Brasil possui diferentes fontes de financiamento e diferentes formas institucionais de sua gestão. Muitas vezes essas fontes e as orientações governamentais são conflitantes. Assim, uma nova política nacional de desenvolvimento regional teria que considerar a possibilidade de fusão dessas fontes em um fundo único, o qual vem sendo discutido no Brasil através do Fundo Nacional de Desenvolvimento Regional. Essa tarefa é complexa porque, além de exigir mudanças constitucionais, ela exige, antes de tudo, um pacto territorial entre a União e os Estados e destes entre si.

Tudo isso implicaria um novo desenho institucional adequado à gestão da nova política. Esse novo desenho, para que tenha racionalidade e eficiência, deveria buscar construir as formas institucionais do Governo Central e da articulação dessas com as instâncias estaduais e de outras escalas subnacionais. Além das dificuldades intrínsecas, surge o problema das atuais instituições de desenvolvimento regional que vêm sendo recriadas, a exemplo da Sudene, Sudam e Sudeco. Ora, a nova regionalização proposta quebra as continuidades territoriais constantes no recorte territorial da atuação dessas instituições. Por sua vez, essas estão sendo recriadas sem uma adequação de propósitos, instrumentos e formas de atuação, correndo o risco de que elas se transformem em "monumentos às necessidades do passado", a exemplo do prédio da Sudene, no Recife.

Um novo ordenamento do território, guiado pelos objetivos de coesão econômica, social e política, depende, fundamentalmente, de duas grandes dimensões com impactos estruturais duradouros: $\mathrm{da}$ infraestrutura, especialmente de transportes e; da nova rede urbana. A infraestrutura de transporte condiciona o sentido dos fluxos e da integração e os demais elementos da infraestrutura e da logística (telecomunicações, energia, armazenamento, entre outros). Por sua vez, o sistema de transportes deve ser analisado tendo em vista a integração inter-regional, em uma perspectiva nacional, e a integração intrarregional. Esta última tem papel decisivo no fortalecimento de novas centralidades.

Uma nova rede urbana acarretaria a necessidade de se escolher ou selecionar novas centralidades urbanas a ser reforçadas, 
com pelo menos duas escalas: uma macro e outra meso ou sub-regional. A escala macro permitiria mudar o desenho dos fluxos macroespaciais, freando o aumento da megaconcentração em alguns centros urbanos (São Paulo, Rio de Janeiro, Belo Horizonte, Porto Alegre, Curitiba, Brasília, Salvador, Recife, Fortaleza e Manaus) e fortalecendo novos macropolos. Esses novos macropolos contribuiriam para integrar outras regiões do País, como centros de consumo e de suporte à produção, neles mesmos e em seus entornos. Os mesopolos ou subpolos contribuiriam para processos semelhantes, em escala mais reduzida. Essa conjugação permitirá a constituição de uma rede urbana mais integrada e melhor distribuída. $\mathrm{O}$ fortalecimento dessas novas centralidades depende, afora a infraestrutura de integração inter e intrarregional, da concentração de equipamentos públicos, que, além da oferta de serviços em si, contribuam para a atração do investimento produtivo privado. Uma orientação de tal natureza estabeleceria condições básicas para a construção de uma nação com metas, talvez "utópicas" ou de longo prazo, de um país policêntrico, integrado em termos territoriais, econômico, social e político.

Por fim, na era do conhecimento ou da sociedade do conhecimento, educação, ciência e tecnologia devem ser vistos como a base estrutural que assegura a cidadania e o avanço científico e tecnológico. Avanço científico e tecnológico como base para uma nação soberana ou menos dependente, econômica e politicamente, para fora, e socialmente, para dentro. 


\section{Referências bibliográficas}

\author{
ALBUQUERQUE, R. C.; \\ CAVALCANTI, C. V. \\ Desenvolvimento regional no Brasil. \\ Brasília, IPEA, 1978. \\ AMENDOLA, M.; BARATA, P. \\ Investimenti industriali e sviluppo \\ dualístico. Roma: Svimez, 1978.
}

AMIN, A.; THIRFT, N. (Eds.). Globalization, institutions, and regional development in Europe. Oxford: Oxford U.P., 1994

BOUDEVILLE, J. Los espacios econômicos. Buenos Aires: Eudeba, 1969

BRENNER, N. Between fixity and motion. Society and Space, v. 16, p. 459-481, 1998.

BRENNER, N. Globalisation and reterritorialisation. Urban Studies, v. 36, n. 3, p. L431-451, 1999.

CANO, W. Raizes da concentração industrial em São Paulo. São Paulo: Editora, 1977.

CANO, W. Desequilibrios regionais e concentração industrial no Brasil. São Paulo: Global, 1985.

CARVALHO, O. Desenvolvimento regional. Rio de Janeiro:

Campus, 1979.

CASTELLS, Manuel. A questão urbana. Rio de Janeiro: Paz e Terra, 1983. (cap.III e IV; Posfácio).
CASTELLS, M.; HALL, P. Technopoles of the world. London: Routledge, 1994.

CEPAL. Estudio económico de América Latina, 1949. New York: ONU CORRAGIO, J. L.

Possibilidades e dificuldades de uma análise espacial contestatório. Demografia e Economia, México, v. XI, n. 2, p.135-154, 1977.

CHENERY, H. B. Development policies for southern Italy. In: FRIEDMAN, J.; ALONSO, W. Regional development and planning. Cambridge: MIT, 1964.

CHINITZ, B. The regional problem in the USA. In: ROBINSON, E.A.G. (ed.)

Backward areas in advanced countries. London: Macmillan, 1969.

CHRISTALLER, W. Central places in Southern Germany (1939). New Jersey: Prentice-Hall, 1966.

$\mathrm{COHN}, \mathrm{A}$. Crise regional e planejamento. São Paulo: Perspectiva, 1976.

CUMBERLAND, J. J. Regional development experiences and prospects in the United States of America. Netherlands: Mouton, 1973.

DATAR. 40 ans d'ámanagement du territoire. Paris: La Documentation Française, 2003.
DINIZ, C. C. Lucas Lopes: o visionário do desenvolvimentismo. Revista do Arquivo Público Mineiro, a. 46, n. 2, jul.-dez. 2008

DINIZ, C. C.; GONÇALVES, E. Economia do conhecimento e desenvolvimento regional. In: DINIZ, C. C.; LEMOS, M. B. Economia e território. Belo Horizonte: Editora da UFMG, 2005.

DINIZ, C. C.; SANTOS, F.; CROCCO, M. Conhecimento, inovação e desenvolvimento regional/local. In: DINIZ, C. C.; CROCCO, M. Economia regional e urbana: contribuições teóricas recentes. Belo Horizonte: Editora da UFMG, 2006.

\section{EUROPEAN UNION.}

Coopération pour l'aménagement $d u$ territoire européen.

CECA-CE-CEEA, Bruxelles, Luxembourg, 1994.

EUROPEAN UNION. European spatial development perspective. Noordwijk, Editora, 1997.

FRIEDMAN, J. The concept of a planning region: the evolution of an idea in the United States. Cidade: Editora, 1961.

FUJITA, M.; KRUGMAN, P.; VENABLES, A. J. The spatial economy: cities, regions, and international trade. Massachusetts: The MIT Press, 1999.
FURTADO, C. Formação econômica do Brasil. São Paulo:

Nacional, 1964.

FURTADO, C. Subdesenvolvimento e estagnação na América Latina. Rio de Janeiro: Civilização Brasileira, 1966.

FURTADO, C. Intra-country discontinuities: Towards a theory of spatial structures. Social Science Information, v. 6, p. 7-14, 1967.

FURTADO, C. Análise do modelo brasileiro. Rio de Janeiro: Civilização Brasileira, 1972.

FURTADO, C. Teoria e política do desenvolvimento econômico. São Paulo: Abril Cultural, 1983.

FURTADO, C. A fantasia organizada. Rio de Janeiro: Paz e Terra, 1985.

FURTADO, C. A fantasia desfeita. Rio de Janeiro: Paz e Terra, 1989.

FURTADO, C. A economia colonial brasileira nos séculos XV e XVII. São Paulo: Hucitec, 2001

GRANOVETTER, M. Economic action and social structure: the problem of embeddedness. American Journal of Sociology, Chicago, v. 91, n. 3, Nov. 1985. 
GRAVIER, J. F. Paris e lê désert français (1947), extrato publicado em DATAR: Lês grands textes de l'Aménagement du territoire e de la décentralisation, organizado por Alvergne C e Musso, P. Paris: La Documentation Française, 2003.

GTDN. Uma politica de desenvolvimento econômico para o Nordeste. Recife: Sudene, 1967.

HALL, P. Urban and regional planning. London: Routledge, 1975.

HIRSCHMAN. A The strategy of economic development. New Haven: Yale University, 1958.

ISARD, W. Location and space-economy. MIT: Cambridge, 1956.

ISARD, W. History of regional science and the regional science association international. New York: Springer, 2003.

ISARD, W. et al. Methods of regional and interregional analysis. London: Alsgate, 1960.

KALDOR, N. Causes of the slow rate of economic growth of the United Kindgom. Cambridge: Cambridge University Press, 1966.

KALDOR, N. The case for regional policies. Scottish Journal of Political Economy, 1970. p. 338-348.

KEEBLE, D. et al. Collective learning processes and inter-firm networking in innovative high-technology regions. Working Paper Series, Cambridge, ESRC Centre for Business Research, University of Cambridge, WP 86, Mar. 1998.
KRUGMAN, P. Development, geography, and economic theory. The MIT Press. Cambridge: Massachusetts, 1991

LAFER, B. M. Planejamento no Brasil. São Paulo:

Perspectiva, 1975.

LEFÈBVRE, Henri. La revolución urbana. Madrid: Alianza, 1972.

LIMA, M. C. Celso Furtado e o Conselho Deliberativo da Sudene. In: LIMA, M. C.; DAVID, M. D. A atualidade do pensamento de Celso Furtado. Goiás: Verbena, 2008.

LOPES, L. Memórias do desenvolvimento. Rio de Janeiro: CPDOC/FGV, 1991.

LOSCH, A. The economics of location (1933). New Haven: Yale University, 1954.

MANHEIM, K. Liberdade, poder e planificação democrática. São Paulo: Mestre Jou, 1951.

MARKUSEN, A. Profit cycles, oligopoly, and regional development. Cambridge, MIT Press, 1985.

MARKUSEN, A. Sticky place in slippery space. Economic Geography, 1995.

MARKUSEN, Ann et al. High tech America: the what, how, where and why of the sunrise industries. Boston: Allen \& Unwin, 1986.

MARKUSEN, Ann et al. Second tier cities, rapid growth beyond the metropolis. Minneapolis: Minnesota University Press, 1999.
MARKUSEN, Ann et al. The rise of the gunbelt: the military remapping of Industrial America. New York, Oxford: Oxford University Press, 1991.

MASSEY, D. Towards a critique of industrial location theory. Center for Environmental Studies. Research paper 5, London, 1974.

\section{MINISTÉRIO DO}

PLANEJAMENTO. Estudo da

dimensão territorial para o

planejamento. Regiões de referência, III. Brasília, 2008.

\section{MINTER-SUDENE.}

Modernização regional em curso: trinta anos de Sudene. Recife, 1990.

MUNFORD, L. The culture of cities. Cidade: Editora, 1938.

MYRDAL, G. Rich lands and poor. New York: Haper and Row, 1957.

\section{NEKRASOV, N. N. Economia} regional. Havana: Editora Científica-Técnica, 1971.

\section{OLIVEIRA, F. Elegia para uma} re(li)gião: Sudene, Nordeste, planejamento e conflito de classes. Rio de Janeiro: Paz e Terra, 1977.

PAELINCK, J. A. Teoria do Desenvolvimento Regional

Polarizado. In: SCHWARTZMAN, J. Economia regional: textos escolhidos. Belo Horizonte: Cedeplar, 1977.

PARK, R. The urban community as a spatial pattern and a moral order. Cidade: Editora, 1926.

PERROUX, F. A economia do século XX. Porto: Herder, 1967.
PRADO JUNIOR, C. Historia econômica do Brasil. São Paulo: Brasiliense, 1969.

PRADO JR. Caio. Formação do Brasil contemporâneo, 1996.

PUTNAM, R. D. Making democrac work: civic traditions in modern Italy. Princeton: Princeton University Press, 1993.

REBOUCAS, O. E. et al. Desenvolvimento do Nordeste: diagnóstico e sugestões de políticas. REN, v. 10, n. 2 , abr./jun. 1979.

ROMER, P. M. The origins of endogenous growth. Journal of Economic Perspectives, v. 8, n. I, p. 3-22, Winter 1994.

ROSTOW, W. W. The stages of economic growth. Economic history review, ago. 1959.

\section{ROTHBLAT, D. N. Regional}

planning: the appalachian experience. Massachusetts: Lexington, 1971.

SALA-I-MARTIN, X. The classical approach to convergence analysis. Economic Journal, n. 106, p. 1019-1036, 1996

SANTOS, Milton. A urbanização brasileira. São Paulo:

Hucitec, 1993.

SIMONSEN, R. História econômica do Brasil, 1500-1820. São Paulo:

Nacional, 1944

STHOR, W. El desarrollo regional in América Latina: experiências. Buenos Aires: SIAP, 1972. 
STORPER, M. The resurgence of regional economies, ten years later: the regional as a nexus of untraded interdependencies.

European urbana and regional studies, v. 2, n. 3, 1995.

STORPER, M.; WALKER, R. The capitalist imperative: territory, technology and industrial growth. New York: Blackwell, 1989.

SWYNGEDOUW, E. A.

The heart of the place: the ressurrection of locality in an age of hyperspace. Geografiska Annsier, v. 71, n. 8,1989 .

VON THUNEN, J. H. Isolated state: an English edition of Der Isoleerte Staaat (1817). Oxford: Pergamon, 1966.

WEBER, Alfred. Theory of the location of industries. Chicago:

Chicago University Press, 1907:1969.

WIRTH, L. The ghetto. Cidade: Editora, 1928.

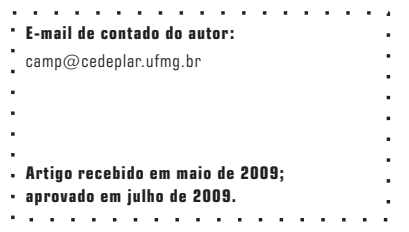

